\title{
Do the competition rules of synchronized swimming encourage undesirable levels of hypoxia?
}

\author{
B. N. Davies PhD, G. C. Donaldson PhD and N. Joels PhD \\ Department of Physiology, Basic Medical Sciences, Queen Mary and Westfield College, Mile End Road, \\ London E1 4NS, UK
}

\begin{abstract}
Recent anecdotal reports that some synchronized swimmers have become dizzy or disorientated towards the end of their performance, and in the worst cases fainted underwater, have caused concern. However, the rules of synchronized swimming encourage slow performance of compulsory figures, and an analysis of the competition placings and duration of underwater sequences showed that the highest rankings were gained by slowly performed compulsory figures and free programmes containing a long underwater sequence. The combination of breath-holding and the vigorous exercise involved suggests that some of the symptoms complained of by the swimmers might be due to hypoxia. We therefore studied the alveolar gas tensions in nine members of the Great Britain National Squad immediately following the performance of set figures and the initial underwater sequence of their free routine in a swimming-bath. All were cyanosed after the underwater sequences of the free routine and reported being mildly confused. The mean(s.d.) alveolar $\mathrm{PO}_{2}$ at this stage was $5.07(1.1) \mathrm{KPa}$, while three girls had an alveolar $\mathrm{PO}_{2}$ below $4 \mathrm{KPa}$, the lowest being $3.67 \mathrm{KPa}$. These gas tensions suggest that potentially dangerous levels of hypoxia may develop during competitive synchronized swimming and that prolonged underwater sequences should not be encouraged.
\end{abstract}

Keywords: synchronized swimming, hypoxia, breathholding

Synchronized swimming is not generally regarded as a hazardous sport, yet it may involve quite lengthy periods of underwater swimming in which the combination of breath-holding and exercise has the potential to lead to the rapid development of hypoxia.

In competitive synchronized swimming individual contestants are required to perform a series of four set figures followed by a free programme lasting $3.5 \mathrm{~min}$. There may be a bias towards prolonged underwater activity in that the rules specify that these set figures should be performed 'slowly' ${ }^{1}$. Moreover, the free programme usually starts with an underwater sequence which may last in excess of $45 \mathrm{~s}$ in the case of more highly placed contestants.

While loss of consciousness during underwater swimming and diving is well documented ${ }^{2}$ there

Address for correspondence: $\operatorname{Dr}$ B. N. Davies appear to be no published reports of loss of consciousness by synchronized swimmers. Nevertheless, a number of competitors have complained of dizziness, disorientation and even momentary blackout during these manoeuvres, more especially when completing the underwater component of the free programme, suggesting that they may indeed be experiencing undesirable levels of hypoxia. These anecdotal reports have prompted the present study in which we have tried to assess the degree of hypoxia at the end of this underwater sequence by measurement of the alveolar gas composition. We have also tried to assess the importance given by judges to the length of time spent continuously submerged by correlating this period with the ranking obtained in competition.

The study was carried out at the invitation of the Amateur Swimming Association of Great Britain. A preliminary account of some of our findings has been communicated to the Physiological Society ${ }^{3}$.

\section{Materials and methods}

\section{Breath-hold times in competition}

At a recent Synchronized Swimming Regional Championship we timed the continuous periods spent underwater during four set figures, the Spiral, Castle, Albatross and Barracuda, performed as described in the Handbook of Synchronised Swimming of the Amateur Swimming Association ${ }^{1}$, and during the initial submerged section of the free programme which was normally the longest period spent underwater.

\section{Alveolar gases following set figures and free programme}

The subjects were nine members of the Great Britain Synchronized Swimming Team and included all members of the 1992 Olympics team. The girls were mean(s.d.) age 18.8(2.2) years (range 15.9-21.9 years) and mean(s.d.) weight $55.9(5.4) \mathrm{kg}$ (range 45.0$64.0 \mathrm{~kg}$ ). All gave informed consent to the study which was approved by the Ethical Committee of the Tower Hamlets Health Authority.

The subjects practised the technique of alveolar gas sampling using a Haldane tube, until the concentrations of $\mathrm{O}_{2}$ and $\mathrm{CO}_{2}$ in duplicate control samples 
SPIRAL
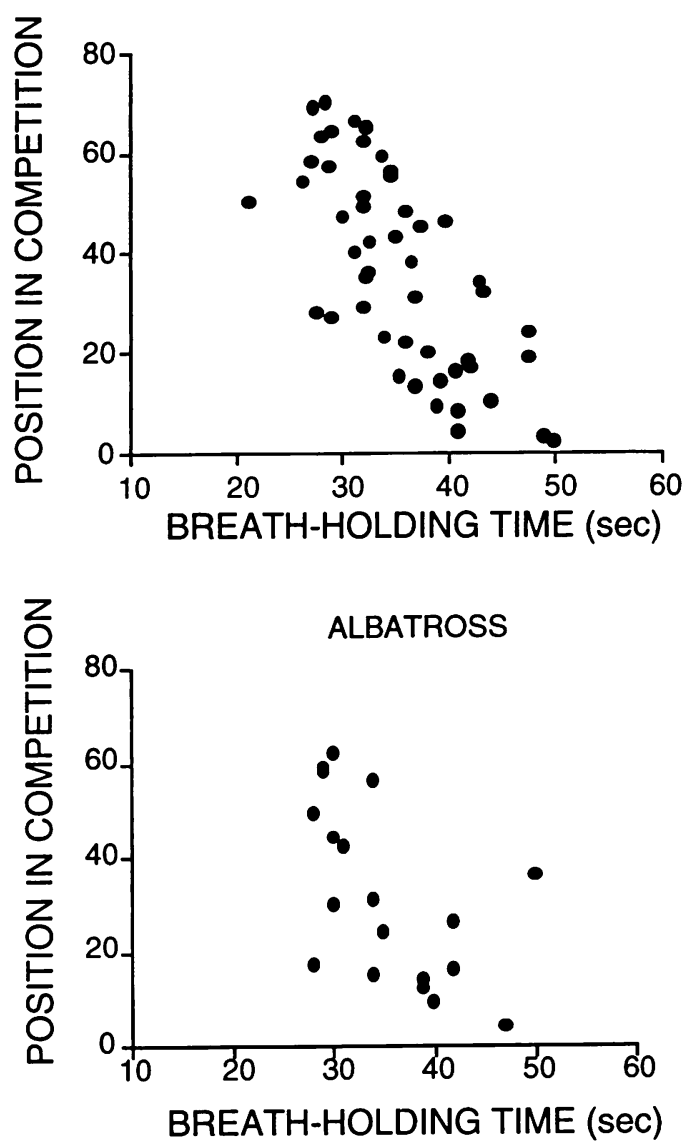

CASTLE
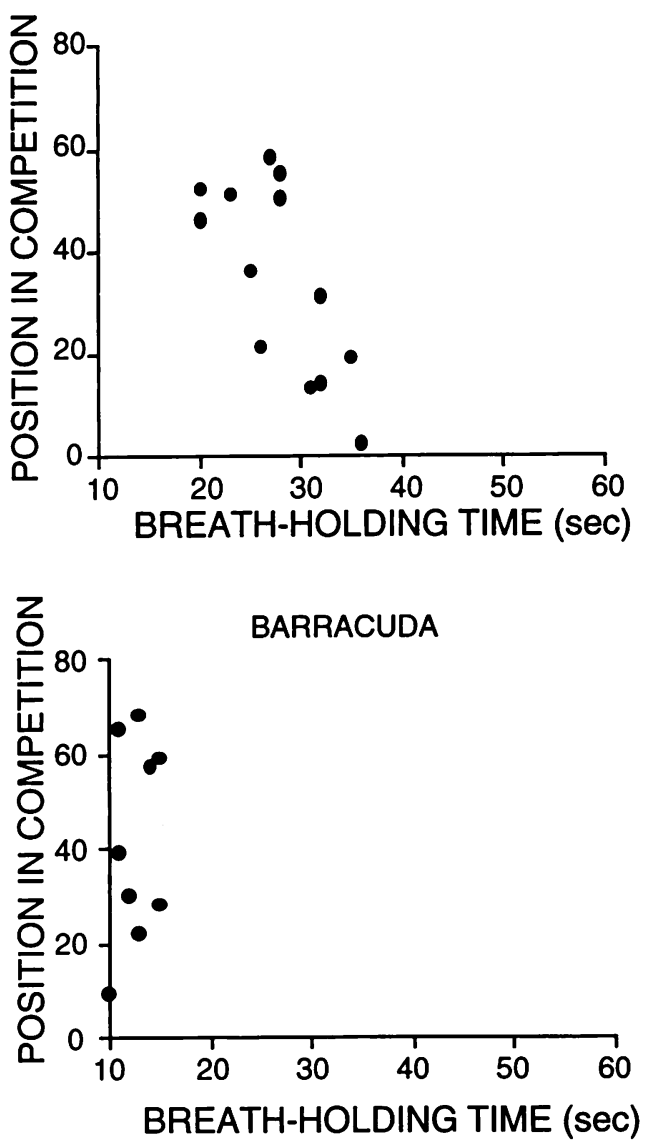

Figure 1. Breath-holding time and ranking in competition for four set figures

differed by no more than $0.2 \%$. They then entered a swimming pool heated to $28-30^{\circ} \mathrm{C}$ where they carried out the initial underwater sequence of their free programme; four subjects also performed two set figures, the Spiral and the Castle. They were asked to ensure that each routine was completed close to the side of the swimming-bath, so that as they finished each manoeuvre they could swim immediately to the side of the pool without drawing a breath, and while still in the water deliver an alveolar gas sample into a Haldane tube held by an observer at the edge of the pool. The samples were withdrawn into syringes and the percentages of $\mathrm{O}_{2}$ and $\mathrm{CO}_{2}$ measured immediately with a paramagnetic $\mathrm{O}_{2}$ analyser $(\mathrm{ZRO} 2, \mathrm{P}$. K. Morgan, Rainham, Kent, UK) and an infra-red $\mathrm{CO}_{2}$ analyser (FM2, P. K. Morgan) calibrated with certified gases of $100 \% \mathrm{~N}_{2}, 100 \% \mathrm{O}_{2}$ and $6 \% \mathrm{CO}_{2}$ in air.

\section{Results}

\section{Breath-hold times and ranking in competition}

Figure 1 shows the relation between the time spent continuously submerged, i.e. breath-hold time, and the ranking obtained for each individual figure. For three of these figures there is an obvious correlation, Spiral $\left(r_{\mathrm{s}}=-0.75, P<0.001\right.$; Spearman rank correlation), Castle $\left(r_{\mathrm{s}}=-0.64, P<0.02\right)$ and Albatross $\left(r_{\mathrm{s}}=\right.$ $-0.643, P<0.01)$, suggesting that the judges attach, whether consciously or not, considerable importance to this aspect. There is no such correlation for the fourth figure, the Barracuda, but while this presents considerable technical difficulty, it is typically of short duration and so does not offer an opportunity to gain higher marks by remaining submerged for a prolonged period.

Figure 2 illustrates the relationship between performance ranking and breath-hold time in the initial

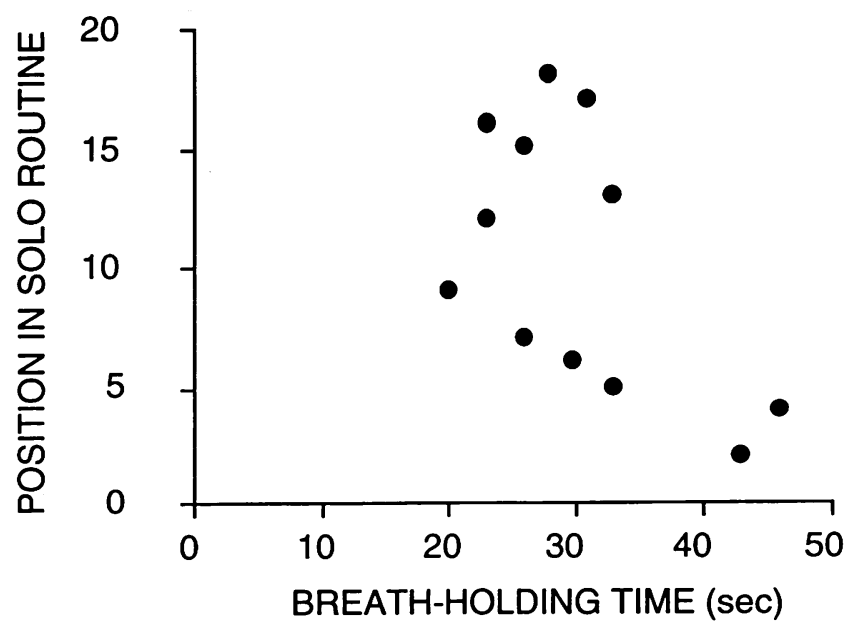

Figure 2. Breath-holding time during inital underwater sequence of free programme and competition ranking 
underwater sequence of the free programme. While there is no clear correlation between breath-hold time and ranking, possibly because the rankings are based not only on this initial component but on the complete performance, it is noteworthy that the two highest scoring performances had the longest continuous underwater programmes.

\section{Alveolar gas tensions}

\section{Set figures}

Four swimmers performed the Spiral and the Albatross. Figure 3 shows that in the Spiral there was a clear relationship between the length of the manoeuvre and the level to which the alveolar $\mathrm{PO}_{2}$ fell. This was less marked with the Albatross, but in both figures the performer who spent the longest time underwater had a final alveolar $\mathrm{PO}_{2}$ of $4.4-4.53 \mathrm{KPa}$.
Free programme

Alveolar gases were measured in nine swimmers immediately after carrying out the initial sequence of their free programme. The findings are displayed in Figure 4. Breath-hold times ranged from 33-66s with a mean(s.d.) of 43.3(10.2) s. At the end of this sequence most of the swimmers appeared centrally cynosed and, when asked, reported being mildly confused. Mean(s.d.) alveolar $\mathrm{PO}_{2}$ at this stage was $5.07(1.12) \mathrm{KPa}$; half the girls had an alveolar $\mathrm{PO}_{2}$ of less than $5.33 \mathrm{KPa}$. The level to which $\mathrm{PO}_{2}$ was reduced was not obviously determined by the length of the performance since oxygen consumption must have been related also to the level of energy expenditure. Nevertheless, three of the five swimmers whose underwater programmes lasted for $40 \mathrm{~s}$ or more reduced their alveolar $\mathrm{PO}_{2}$ below $4 \mathrm{KPa}$.

Mean(s.d.) alveolar $\mathrm{PCO}_{2}$ at the end of the period of submergence was $7.39(0.45) \mathrm{KPa}$; range 6.85$8.09 \mathrm{KPa}$. Although Figure 4 suggests a tendency to a
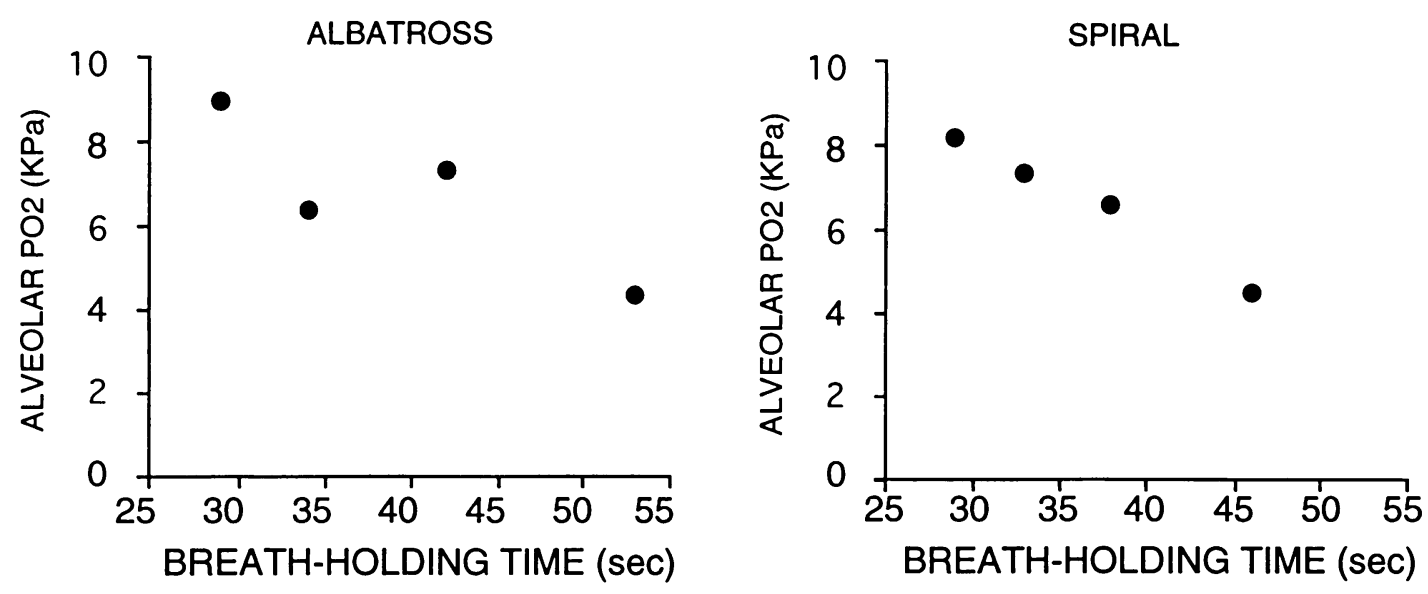

Figure 3. Duration of breath-holding and alveolar $\mathrm{PO}_{2}$ on completion of Spiral and Albatross figures

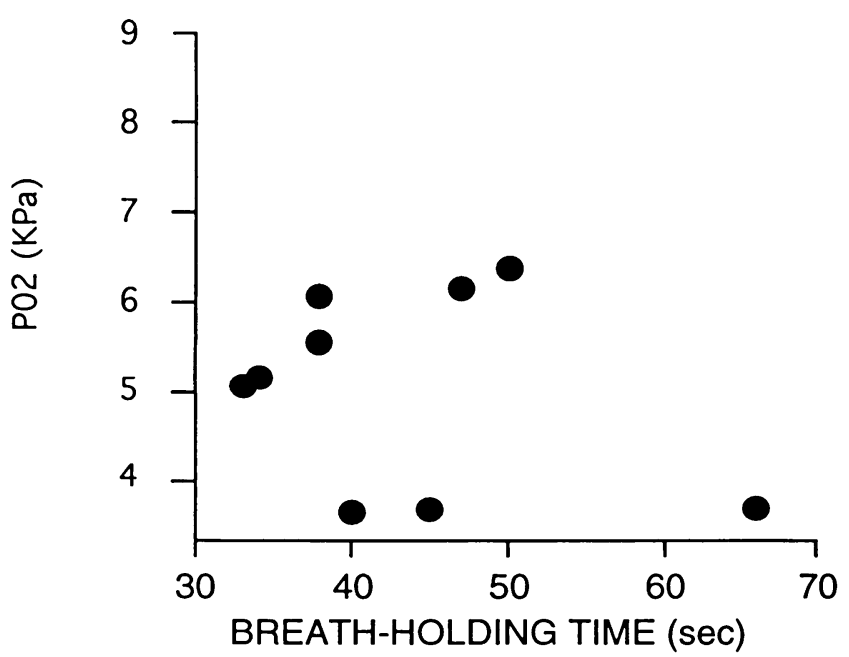

a

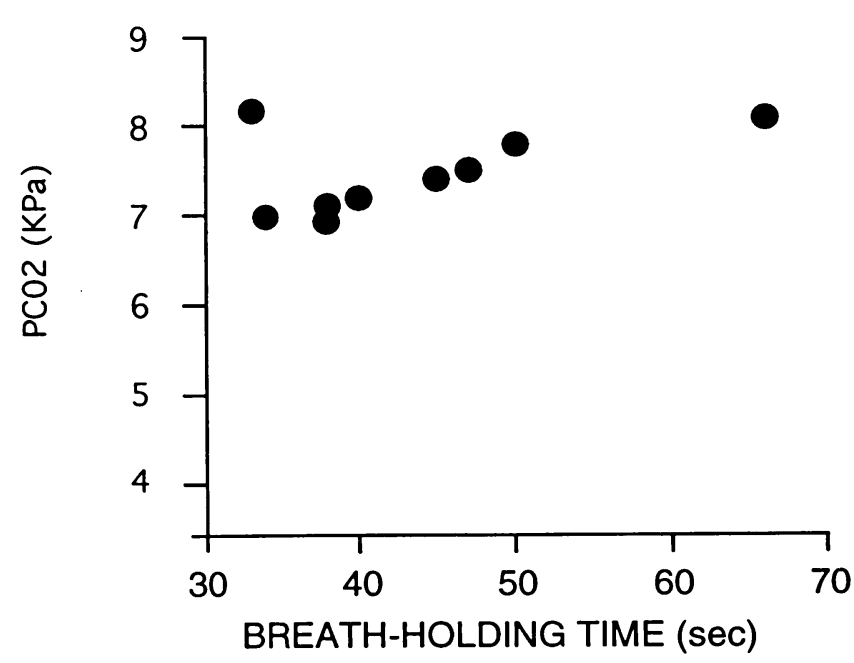

b

Figure 4. Duration of breath-holding and alveolar $\mathrm{PO}_{2}$ (a) and $\mathrm{PCO}_{2}$ (b) at end of initial underwater sequence of free programme 
relationship between the duration of breath-holding and the level to which the $\mathrm{PCO}_{2}$ rose, this was not significant.

\section{Discussion}

There have been several previous investigations of synchronized swimmers. These include studies of lung volumes and the ventilatory responses to hypoxia and hypercapnia ${ }^{4}$, aerobic and anaerobic work capacity ${ }^{5}$, muscular power output ${ }^{6}$ and heart rate recorded by radiotelemetry during a number of competitive figures ${ }^{7}$. While the use of the rise in heart rate as an index of the severity of exercise in synchronized swimming is complicated by the effects of submergence and postural changes, the last of these papers ${ }^{7}$ reported heart rates in the region of 140 beats per minute at the end of the Castle manoeuvre. A recently published account ${ }^{8}$ of heart rate and blood lactate concentration during synchronized swimming included measurements of alveolar gases at the completion of the Heron manoeuvre, a set figure which requires about $45 \mathrm{~s}$ breath-holding but which is of a lesser degree of difficulty than those examined in this study. Alveolar $\mathrm{PO}_{2}$ at this time was $8 \mathrm{KPa}$, a level of mild hypoxia which would not be expected to give rise to the problems which prompted the present study. However, as the authors themselves point out, their measurements of heart rate and blood lactate concentration indicate a higher rate of energy expenditure during freestyle routines. We believe that our findings provide the first evidence of the extent to which the alveolar gases may change under conditions mimicking the more rigorous demands of competitive performance.

The mean level of alveolar, and by inference arterial, oxygen tension found in the nine synchronized swimmers at the end of the underwater sequence of their free performance was $5.07 \mathrm{KPa}$, in three of the girls the $\mathrm{PO}_{2}$ being only $3.6-3.73 \mathrm{KPa}$. This level of $\mathrm{PO}_{2}$, which in conjunction with the hypercapnia and any lactacidosis would be accompanied by a considerable degree of haemoglobin desaturation, represents a degree of hypoxia often associated with loss of consciousness ${ }^{9}$. It would therefore be consistent with the central cyanosis and apparent confusion noted by the observers at this stage. By comparison, the lowest value for alveolar $\mathrm{PO}_{2}$ found in a group of Korean diving women who performed dives of similar duration (37-50 s) to a depth of $11 \mathrm{~m}$ was $5.07 \mathrm{KPa}^{10}$. The greater degree of hypoxia seen in the synchronized swimmers is an indication of the considerable muscular work involved in this activity, where an elegant limb held motionless above the surface gives no indication of the dynamic effort required below to maintain this posture.

The mean alveolar $\mathrm{PCO}_{2}$ at the end of the underwater sequence was $7.39 \mathrm{KPa}$. Synchronized swimmers are aware of the dangers of hyperventilation prior to a dive and, although they rarely submerge to a depth greater than $2 \mathrm{~m}$, are taught not to indulge in this practice beyond the taking of one or two deep breaths. Nor do they start the underwater sequence with much more than a normal tidal volume in their lungs since the added buoyancy would make it more difficult for them to maintain a posture underwater. This rise in $\mathrm{PCO}_{2}$ will have mixed effects. On the one hand by shifting the haemoglobin dissociation curve to the right it will further reduce uptake of oxygen by the blood as it passes through the lungs. On the other hand it will improve cerebral blood flow by its vasodilator action. Moreover, through its respiratory stimulant action, it may limit the swimmer's ability to continue breathholding and thus diminish the risk of dangerous levels of hypoxia in less determined individuals.

Thus, in competition, synchronized swimmers may be exposed to undesirable levels of hypoxia. However, as the relationship which we have found between the length of time spent under water and the ranking achieved in both the set figures and the free performance have shown, there is a tendency for judges to favour prolonged submergence in competition. In view of our findings we feel that less importance should be placed on this feature and would suggest that underwater sequences should be limited at most to $40-45 \mathrm{~s}$. We understand that in consequence the word 'slowly' has now been deleted from the instructions regarding the set figures in the Association's synchronized swimming handbook.

\section{Acknowledgements}

We are grateful to Ms Janet Holstock, the National squad team manager, and to all the subjects for their co-operation. Technical assistance was given by Mr W. Curry and Ms Lois Kua, and Drs K. Mirhda and M. Scarborough provided medical supervision. We would also like to express appreciation to Ms J. Goldstone who made available to us the swimming pool in the Nurses' Home of St Bartholomew's Hospital for these experiments. The Amateur Swimming Association kindly provided financial assistance for this study.

\section{References}

1 Amateur Swimming Association. Handbook of Synchronised Swimming. 1988; 7.

2 Craig AB. Summary of 58 cases of loss of consciousness during underwater swimming and diving. Med Sci Sports 1976; 8: 171-5.

3 Davies BN, Joels N, Udoh FI. Hypoxia: a potential danger in synchronized swimming. J Physiol 1993; 467: 118.

4 Bjurstrom RL, Schoene RB. Control of ventilation in élite synchronized swimmers. J Appl Physiol 1987; 63: 1019-24.

5 Roby FB, Buono MJ, Constable SH, Lowdon BJ, Tsao WY. Physiological characteristics of champion synchronized swimmers. The Physician and Sports Medicine 1983; 11: 136-47.

6 Takamoto M, Nakamura Y, Motoyoshi M, Mutoh Y, Miyashita M. Physiological characteristics of Japanese élite synchronized swimmers. Internationsl Series on Sports Sciences 1988; 18: Swimming Science V: 121-8.

7 Gemma KE, Wells CL. Heart rates of élite synchronized swimmers. The Physician and Sports Medicine 1987; 15: 99-106.

8 Figura F, Cama G, Guidetti L. Heart rate, alveolar gases and blood lactate during synchronized swimming. J Sports Sci 1993; 11: 103-7.

9 Craig AB Jr. Causes of loss of consciousness during underwater swimming. J Appl Physiol 1961; 16: 583-6.

10 Hong SK, Rahn H, Kang DH, Song SH, Kang BS. Diving pattern, lung volumes and alveolar gas of the Korean diving woman (ama) J Appl Physiol 1963; 18: 457-65. 